\title{
Entre raça e gênero: significado das cotas raciais para universitárias negras
}

\section{Between race and gender: meaning of racial quotas for black university students}

\section{Entre raza y género: significado de las cuotas raciales para universitarias negras}

\author{
João Paulo Lopes dos Santos ${ }^{1}$ \\ Nubia Regina Moreira ${ }^{1}$
}

DOI: http://dx.doi.org/10.20435/serie-estudos.v20i52.1222

\begin{abstract}
Resumo: Este estudo objetiva analisar o significado das cotas raciais para quatro estudantes negras, cotistas da Universidade Estadual do Sudoeste da Bahia. Para tal, utilizamos dados do Instituto de Pesquisa Econômica Aplicada (IPEA), os quais mostram as discrepâncias entre negros/as e branco/ as no Ensino Superior. Os aspectos metodológicos se fundamentam na perspectiva relacional potencializada por Pierre Bourdieu. Desse modo, a abordagem qualitativa foi estruturada a partir do uso de entrevistas. Observou-se a essencialidade das cotas raciais como canais possibilitadores de inserção de negros/as no Ensino Superior. Assim, a inexistência destas limitaria ainda mais a presença deles/as na universidade. Contudo, as cotas raciais, apesar de ensejarem avanços, ainda não conseguiram mitigar o racismo e promover a igualdade racial.
\end{abstract}

Palavras-chave: cotas raciais; Ensino Superior; estudantes negras.

Abstract: This study aims to analyze the significance of the racial quotas for four black students, quota holders of the Southwestern Bahia State University. For this, we use data from the Institute for Applied Economic Research (IPEA), which show the discrepancies between blacks and whites in Higher Education. The methodological aspects are based on the relational perspective potencialized by Pierre Bourdieu. Therefore, the qualitative approach was structured from the use of interviews. It was observed the essentiality of the racial quotas as enablers channels for the insertion of blacks in Higher Education. So, the inexistence of them would taper even more their presence in the university. However, racial quotas, despite advances, could not mitigate racism and promote racial equality yet.

Keywords: racial quotas; Higher Education; black students.

Resumen: Este estudio objetiva analizar el significado de las cuotas raciales para cuatro estudiantes negras, cotistas de la Universidad Estatal del Sudoeste de Bahía. Para ello, utilizamos datos del

\footnotetext{
${ }^{1}$ Universidade Estadual do Sudoeste da Bahia (UESB), Vitória da Conquista, Bahia, Brasil.
} 
Instituto de Investigación Económica Aplicada (IPEA), los cuales muestran las discrepancias entre negros/as y blanco/as en la Enseñanza Superior. Los aspectos metodológicos se fundamentan en la perspectiva relacional potencializada por Pierre Bourdieu. De este modo, el enfoque cualitativo fue estructurado a partir del uso de entrevistas. Se observó la esencialidad de las cuotas raciales como canales posibilitadores de inserción de negros/as en la Enseñanza Superior. Así, su inexistencia limitaría aún más la presencia de ellos/ellas en la universidad. Sin embargo, las cuotas raciales, a pesar de que dan lugar a avances, aún no lograron mitigar el racismo y promover la igualdad racial.

Palabras clave: cotas raciales; Enseñanza Superior; estudiantes negras.

\section{INTRODUÇÃO}

As reivindicações da população negra brasileira por reparações, mediadas pelos movimentos negros e seus coletivos, proporcionaram o que atualmente se estabelece como políticas de Ações Afirmativas. Contudo tais diligências não são manifestações que ganharam força nos dias atuais, elas foram enviesadas ao longo do século XX nas múltiplas mobilizações. Nesse percurso, governo e grupos sociais hegemônicos permaneceram alheios às demandas dos afro-brasileiros. No entanto, por ocasião da III Conferência Mundial de Combate ao Racismo, Discriminação Racial, Xenofobia e Intolerância Correlata, o Brasil assumiu a responsabilidade de compor e tornar factíveis políticas de enfrentamento ao racismo e qualquer espécie de discriminação racial.

Nessa esteira, insere-se o debate sobre as cotas raciais enquanto política institucional aceita por diversas universidades públicas do país. Assim, o presente artigo, de abordagem qualitativa, tem como objetivo analisar e, consequentemente, apresentar o significado atribuído às cotas raciais através das narrativas de quatro alunas negras cotistas de cursos de licenciatura instituídos após a implementação do sistema de cotas na Universidade Estadual do Sudoeste da Bahia, campus de Vitória da Conquista, em 2008. As falas foram estruturadas a partir de questionamentos que buscaram entender a relevância das cotas raciais na trajetória escolar no Ensino Superior dessas alunas e a possibilidade ou não de ingresso na universidade numa conjuntura da não existência desse mecanismo de Ação Afirmativa.

Os resultados, associados aos relatos das estudantes, apontaram para a essencialidade das cotas raciais como um dos canais possibilitadores de inserção de negros/as no Ensino Superior. Pode-se dizer que a inexistência dessa política, assim com as demais políticas de Ações Afirmativas, afunilaria ainda mais a pre- 
sença da população negra na universidade, haja vista a realidade discrepante da qualidade do ensino público brasileiro experimentado por segmentos distintos em diferentes modalidades de ensino, associado à pobreza e à discriminação racial. Contudo, apesar das políticas de Ações Afirmativas serem uma realidade no Brasil, o que se percebe é que elas ainda não conseguiram mitigar o racismo e promover a igualdade racial. O Instituto de Pesquisa Econômica Aplicada (IPEA) corrobora essas assertivas quando traz em suas publicações os baixos índices de escolarização líquida de negros/as na Educação Superior. Segundo o Instituto, 25\% da população que se considera branca frequenta esse nível de educação, enquanto o contingente negro (soma de pretos e pardos) corresponde a apenas 12,5\% nesta mesma modalidade de ensino (IPEA, 2016).

Os dados indicam ainda que a população branca com 25 anos ou mais de idade e que possui 12 anos ou mais de estudos apresenta os seguintes índices: $24,4 \%$ para o contingente masculino e $27,1 \%$ para o feminino. Com relação às mulheres negras e aos homens negros na mesma faixa etária citada e com o tempo de estudo igual ao mencionado, a taxa é de $13,7 \%$ e 10,1\%, respectivamente (IPEA, 2015).

Com referência à população branca, a taxa bruta de matrículas em 2015 era de 46\%; por outro lado, pretos/as e pardos/as somavam percentagens que representavam quase a metade da taxa inerente à população branca, ou seja, $28,7 \%$ e $25,7 \%$, respectivamente. Esse panorama mostra a presença ainda mínima de negros/as nas universidades públicas do Brasil. Indubitavelmente, ao se comparar os dados apresentados com outros de anos anteriores, percebe-se uma ampliação do acesso de negros/as nas universidades, viabilizado, principalmente, pelas políticas de Ações Afirmativas.

\section{POLÍTICAS DE AÇÃO AFIRMATIVA: TÁTICAS ANTIRRACISTAS E DE COMBATE À DISCRIMINAÇÃO RACIAL}

As questões raciais no Brasil têm ensejado palco para discussões controversas entre grupos - classicamente dissociados - de esquerda e direita que disputam espaços de representatividade social. Os confrontos que estão atravessados pelo racismo, a exemplo das ocorrências de hostilidade das corporações policiais em direção aos negros, possibilitam estratégias e linhas de argumentações de na- 
tureza racial nos mais diferentes campos (social, cultural, educacional, político, econômico) em que esses conflitos se exteriorizam.

Ao compreender essas relações conflitantes e racialmente discriminatórias, as organizações negras que compõem o Movimento Negro brasileiro e parte da comunidade epistêmica iniciaram um processo de mobilização política e cultural que se contrapõe às desigualdades raciais. Desse modo, "[...] o movimento dos negros brasileiros contra as desigualdades raciais é sem dúvida uma importante forma de mobilização social no Brasil de hoje" (GUIMARÃES, 2003, p. 249).

O contexto de influências criado nesse ínterim, paulatinamente, abriu caminhos para que essas organizações negras demandassem do governo federal políticas de Ações Afirmativas em um dos setores mais visados por seus militantes, o educacional. As políticas de Ações Afirmativas passaram, portanto, a configurar a pauta da agenda pública tão só com o início do decurso de redemocratização do Brasil, ocasião na qual diferentes movimentos e organizações sociais, anteriormente emudecidos pela ditadura, começaram a reclamar seus direitos explicitamente.

O Movimento Negro, enquanto movimento social e político, surgiu nos anos 1970 e, desde então, iniciou-se a articulação das lutas por direitos e igualdade entre brancos e negros. O acesso à educação, nesse contexto, é o meio fundamental para uma equalização social mais ajustada às pretensões do Movimento (LOPES, 2014).

Em 1978, várias agremiações políticas e culturais negras se encontraram na cidade de São Paulo para instituir o Movimento Negro Unificado contra a Discriminação Racial. As razões pelas quais passaram a lutar nesse período se diferenciavam daquelas prescritas pelas tradições das organizações negras paulistas nos anos $1920^{2}$.

Nessa esteira, já não se discutia mais, nos movimentos negros, ou seja, nas várias faç̧ões do Movimento Negro, o preconceito, mas sim a discriminação racial. Este foi um fator preponderante que sobrelevou, em comparação às décadas

\footnotetext{
${ }^{2}$ Naqueles tempos, as organizações negras nutriam o diagnóstico segundo o qual, mesmo que o "preconceito de cor" fosse um empecilho para o desenvolvimento e a integração social do povo negro brasileiro, o principal problema estava nos próprios negros, principalmente na carência de condições para competir no mercado de trabalho, em vista da precariedade de educação formal, ausência de boas maneiras e falta de união entre eles, ou seja, dada a fraqueza das organizações negras, tidas como incapazes de promover o avanço social dos membros da "raça" (GUIMARÃES, 2003, p. 248).
} 
precedentes, as lutas da população negra a partir da década de 1970. “A pobreza negra passou a ser tributada às desigualdades de tratamento e de oportunidades de cunho 'racial' (e não apenas de cor)" (GUIMARÃES, 2003, p. 248).

Segundo Guimarães (2003), o retrato técnico inerente à natureza racial das discrepâncias sociais no Brasil já era patente desde a década de 1980, sobretudo para além das fronteiras do território nacional. Nesse sentido, as reivindicações do Movimento Negro já ressoavam nesse período, limiarmente, através da queixa estremada do deputado Abdias do Nascimento (AZEVEDO, 2004).

A instabilidade educacional brasileira, principalmente quando se trata do acesso limitado de negros/as ao Ensino Superior, a qualidade precária e heterogênea da escola básica pública, como também a considerável desproporcionalidade racial existente em todas as modalidades de ensino, já configuravam como pautas de discussões de intelectuais e políticos quando Fernando Henrique Cardoso tomou posse, em 1995 (GUIMARÃES, 2003).

Efetivamente, os debates acerca das políticas de Ação Afirmativa só encontrariam espaço na agenda pública brasileira no início dos anos 2000, antecedida, no entanto, pela Marcha Zumbi ${ }^{3}$ dos Palmares contra o Racismo, pela Cidadania e a Vida, ocorrida em Brasília, no ano de 1995. Este evento assinalou o estreitamento entre as demandas dos movimentos negros e os terrenos representativos do governo (SANTOS, 2014).

De modo preciso, os clamores proferidos na Marcha reforçaram as denúncias de racismo e discriminação racial, forçando o governo a encarregar-se de responder rapidamente à mobilização. Consequentemente, o governo de Fernando Henrique Cardoso criou no Ministério da Justiça o Grupo de Trabalho Interministerial de Valorização da População Negra, com a responsabilidade de sugerir ações complementares no enfrentamento da discriminação racial e, da mesma forma, propor e fomentar políticas de fortalecimento da cidadania do contingente negro (JACCOUD, 2009).

Para Santos (2014), somente duas políticas de Ações Afirmativas convergidas ao segmento negro foram instituídas pelo governo FHC, já em seu final de

\footnotetext{
${ }^{3}$ Zumbi, líder do Quilombo dos Palmares, que se localizava na Serra da Barriga, na então Capitania de Pernambuco, opôs-se intrepidamente aos portugueses e aos holandeses, foi tomado como símbolo da resistência negra e reconhecido em 1995 como herói nacional brasileiro (GUIMARÃES, 2003).
} 
mandato. A primeira, efetuada pelo Ministério das Relações Exteriores em 2002, concedia bolsas de incentivo para estudantes negros, com o objetivo de habilitá-los a prestarem concurso na área diplomática. Posteriormente, já no governo Lula, esse programa se manteve e foi expandido. As bolsas concedidas passaram de 20 para 134. Nesse período, foram aprovados e admitidos pelo Ministério das Relações Exteriores 11 bolsistas.

A segunda contemplava o campo educacional, com o Programa Diversidade na Universidade do Ministério da Educação, instituído por meio da Lei n. 10.558/2002. Seu objetivo era oportunizar o ingresso no Ensino Superior de frações socialmente marginalizadas, como os/as negros/as e os/as indígenas oriundos/ as de cursinhos pré-vestibulares comunitários ou cursinhos preparatórios para afro-brasileiros/as carentes (SANTOS, 2014).

Para Guimarães (2009), o governo FHC atuou apenas no direcionamento das negociações e dos debates acerca das Ações Afirmativas para o contingente negro. "Discussão ainda incipiente, pois no Brasil, propostas desse tipo tinham sido, até então, raras e pouco aceitas, mormente quando dirigidas para a população negra" (GUIMARÃES, 2009).

Ao findar a era FHC, as discussões inerentes à integração dos/as negros/as no Ensino Superior público já se encontravam em grande ebulição. As demandas da mobilização negra que almejavam ampliar o ingresso dos afro-brasileiros nas universidades públicas lograram algumas posições satisfatórias dos setores governamentais, sobretudo no decurso dos anos 2000 (SANTOS, 2014).

Essa efervescência, contudo, é tributária aos movimentos negros do Brasil, que, à esteira da III Conferência Mundial de Combate ao Racismo, Discriminação Racial, Xenofobia e Intolerância Correlata, realizada em Durban em 2001, na África do Sul, demandaram com mais veemência igualdade de direitos, forçando, assim, a renovação da pauta de combate ao racismo no país.

A partir de 2003, sob a orientação do governo Lula e em um contexto institucional diferente, os movimentos negros se tornaram governo (DAFLON; FERES JUNIOR; CAMPOS, 2012). Neste período, transcorreu a abertura dos departamentos governamentais aos integrantes desses movimentos, marcada, sobretudo, pela fundação da Secretaria Especial de Políticas de Promoção da Igualdade Racial (SEPPIR), em 21 de março de 2003. Assim, o Movimento Negro começou a figurar nos debates e nas elaborações de políticas sociais. 
Nesse período, as questões raciais ganharam foco, o que possibilitou a expansão das fronteiras de articulação governamental nesse ponto. Logo, o campo da educação foi o que mais sentiu as importantes evoluções no que cerne à implementação de políticas afirmativas (SANTOS, 2014).

Indubitavelmente, para que as desigualdades raciais sejam reduzidas, é imprescindível a interferência do governo através da elaboração de políticas e ações sólidas e interligadas, deliberadas a partir de contextos comuns entre sociedade, movimentos sociais e a esfera governamental. Assim, observa-se a evolução de tais questões em diversos espaços resistentes à temática, notadamente, no campo do Ensino Superior. O quadro a seguir traz um retrato das políticas educacionais no âmbito federal com configuração racial, fomentadas a partir de 2003 e alicerçadas no reconhecimento identitário e na perspectiva redistributiva (LIMA, 2010).

Quadro 1 - Políticas no campo educacional com viés racial

\begin{tabular}{|l|l|}
\hline Lei 10.639, de 2003 & $\begin{array}{l}\text { Altera a Lei 9.394, de } 20 \text { de dezembro de 1996, que } \\
\text { estabelece as diretrizes e as bases da educação nacio- } \\
\text { nal, para incluir no currículo oficial da Rede de Ensino a } \\
\text { obrigatoriedade da temática "História e Cultura Afro- } \\
\text {-Brasileira" }\end{array}$ \\
\hline $\begin{array}{l}\text { Programa Universidade para } \\
\text { Todos (Prouni) }\end{array}$ & $\begin{array}{l}\text { Medida Provisória 213/set. 2004; Projeto de Lei } \\
\text { 3.582/2004; Lei 11.096/jan. 2005. Programa de bolsas } \\
\text { (integral e parcial) para a população de baixa renda. } \\
\text { Parte das bolsas deve ser destinada a estudantes ne- } \\
\text { gros e indígenas, seguindo a proporção desses grupos }\end{array}$ \\
\hline $\begin{array}{l}\text { étnicos na população de cada estado. } \\
\text { Estudande de Financiamento ao de Nível Superior } \\
\text { (Fies) }\end{array}$ & $\begin{array}{l}\text { Portaria n. 30, de 12 de agosto de 2004. } \\
\text { Inclusão do quesito cor na composição do índice de } \\
\text { classificação para seleção de beneficiários. }\end{array}$ \\
\hline
\end{tabular}




\begin{tabular}{|c|c|}
\hline $\begin{array}{l}\text { Secretaria de Educação } \\
\text { Continuada, Alfabetização } \\
\text { e Diversidade (Secad) }\end{array}$ & $\begin{array}{l}\text { Criada em julho de } 2004 . \\
\text { Principais programas: } \\
\text { 1. Educação Quilombola - apoio técnico e fi- } \\
\text { nanceiro aos municípios que possuem áreas de } \\
\text { remanescentes de quilombos. } \\
\text { 2. Programa Diversidade na Universidade, Projetos } \\
\text { Inovadores de Cursos (PIC) - apoio a instituições } \\
\text { que tenham, pelo menos, um ano de experiência } \\
\text { na gestão de projetos educativos inovadores vol- } \\
\text { tados a grupos socialmente desfavorecidos. Para } \\
\text { concorrer ao financiamento, as instituições de- } \\
\text { vem ter ao menos } 51 \% \text { de afrodescendentes e/ou } \\
\text { indígenas entre os alunos matriculados e repassar } \\
\text { entre } 40 \% \text { e } 50 \% \text { do valor recebido para os estu- } \\
\text { dantes, a título de bolsa de manutenção. } \\
\text { 3. Conexões de Saberes - apoio a jovens universitários } \\
\text { de origem popular na produção de conhecimentos } \\
\text { científicos para intervenção em seus territórios de } \\
\text { origem. Diversas ações na formação de professores } \\
\text { para os novos conteúdos, seguindo a Lei } 10.639 \text {. } \\
\text { 4. Tutoria de Ensino Médio - nesta experiência, a } \\
\text { Secad ofereceu } 720 \text { bolsas de permanência para } \\
\text { alunos afro-brasileiros que estão cursando o Ensi- } \\
\text { no Médio. }\end{array}$ \\
\hline $\begin{array}{l}\text { Projeto Gênero e } \\
\text { Diversidade na Escola (2004) }\end{array}$ & $\begin{array}{l}\text { Seppir/MEC/British Council/Centro Latino-Americano } \\
\text { em Sexualidade e Direitos Humanos (Clam)/UERJ. } \\
\text { Formar educadores com base nos temas gênero, } \\
\text { relações raciais e orientação sexual. }\end{array}$ \\
\hline $\begin{array}{l}\text { Introdução do Recorte Racial } \\
\text { no Censo Escolar (2005) }\end{array}$ & $\begin{array}{l}\text { Seppir/Inep. } \\
\text { As fichas de matrícula de escolas de educação } \\
\text { básica passam a conter a indicação da cor do aluno, } \\
\text { autodeclarada por ele próprio, em caso de ter mais } \\
\text { de } 16 \text { anos, e pelos pais ou responsáveis, no caso } \\
\text { de alunos com menos de } 16 \text { anos. }\end{array}$ \\
\hline $\begin{array}{l}\text { Instituição da Comissão } \\
\text { Técnica Nacional de } \\
\text { Diversidade para Assuntos } \\
\text { Relacionados à Educação dos } \\
\text { Afro-Brasileiros (Cadara) - } \\
\text { MEC/Secad, } 2005\end{array}$ & $\begin{array}{l}\text { Acompanhar, analisar e avaliar as políticas educacio- } \\
\text { nais voltadas ao fiel cumprimento do disposto na Lei } \\
\text { 10.639. }\end{array}$ \\
\hline
\end{tabular}




\begin{tabular}{|l|l|}
\hline Ministério da Educação & Resolução 14, de 28 de abril de 2008. \\
- Fundo Nacional de & Programa de Ações Afirmativas para a Popula- \\
Desenvolvimento da & ção Negra nas Instituições Federais e Estaduais de \\
Educação (FNDE) & Educação Superior (Uniafro) - apoiar e incentivar o \\
& fortalecimento e a institucionalização das atividades \\
& nos Núcleos de Estudos Afro-Brasileiros (Neabs) ou \\
grupos correlatos das instituições públicas de educa- & ção superior. \\
\hline
\end{tabular}

Fonte: Elaboração própria (2017).

Diante do quadro, percebem-se iniciativas elaboradas no intuito de transformar o cenário de desigualdade racial existente no Brasil. Porém não se pode afirmar que estes avanços proporcionaram a superação do racismo no país, haja vista que, por exemplo, a Lei n. 10.639/2003, sancionada pelo governo Lula, que trata da obrigatoriedade de inserir no currículo escolar do Ensino Fundamental e Médio a temática "História da África e Cultura Afro-Brasileira", apresenta-se no campo das ações valorativas, no qual sua implementação não se traduz na concretização de políticas de Ação Afirmativa (SANTOS, 2014).

Ainda que as bases das discussões sobre Ações Afirmativas se finquem no âmbito das universidades públicas, é preciso destacar que as instituições privadas também admitem tais mecanismos. Assim, o Prouni se configura como instrumento predominante de acesso ao Ensino Superior privado, tornando-se a política de maior repercussão (DAFLON; FERES JUNIOR; CAMPOS, 2012).

Certamente, o Prouni é um programa de Ação Afirmativa que possibilita o acesso ao Ensino Superior mediante a instituição do mecanismo de cotas (destinadas a alunos/as provenientes de escolas públicas, que se autodeclaram negros/ as e indígenas). Este programa foi implementado através da Medida Provisória (MP) n. 213, de 10 de setembro de 2004, consequentemente, transformada na Lei n. 11.096, de 13 de janeiro de 2005 (SANTOS, 2014).

Todavia, para Santos (2014), tanto o programa Diversidade na Universidade fomentado no governo FHC quanto o Prouni do governo Lula foram esforços perpetrados num contexto de influências, principalmente a partir da Conferência de Durban, que impulsionou também, por exemplo, entre outras demandas, as reivindicações dos movimentos negros pelo estabelecimento das cotas para estudantes negros/as nas instituições públicas brasileiras. 


\section{LEGISLAÇÃO N. 12.711 E A QUESTÃO DAS COTAS RACIAIS PARA NEGROS/AS}

Os debates que contornam a problemática das desigualdades raciais no acesso ao Ensino Superior possibilitaram, desde a última década, a elaboração de políticas de Ação Afirmativa - a citar a Lei 12.711/2012, conhecida como a Lei de Cotas - direcionadas à reparação das desproporcionalidades que atingem a população negra em todo o seu percurso histórico (SENKEVICS, 2017).

No bojo das discussões sobre a recente Lei de Cotas, é importante ressaltar que, mesmo antes de sua implementação, já havia, no início da década passada, um movimento limiar que deliberava sobre a efetivação de Ações Afirmativas de acesso ao Ensino Superior pelo contingente negro mediante sistema de cotas. Portanto as cotas se consolidaram, primeiramente, em dois estados brasileiros cuja população é de maioria negra: Rio de Janeiro e Bahia, assim como apresenta Guimarães (2003, p. 260):

[...] em 9 de novembro de 2001, o Governador Garotinho, do Rio de Janeiro, sancionou a Lei n. 3.708, que reserva um mínimo de $40 \%$ de vagas nas universidades estaduais cariocas (a Universidade do Estado do Rio de Janeiro e a Universidade Estadual do Norte Fluminense) a estudantes "negros e pardos". Essa Lei modificou a de n. 3.524/2000, assinada pelo mesmo Garotinho, que reservou $50 \%$ das vagas da Uerj e Uenf aos estudantes oriundos de escolas públicas. Em 20 de julho de 2002, a Universidade do Estado da Bahia - Uneb -, pela resolução n. 196/2002, segue o mesmo caminho, reservando 40\% das suas vagas de vestibular aos afrodescendentes (pretos e pardos).

A primeira universidade federal a adotar o sistema de cotas para negros e indígenas em seu processo seletivo, mesmo antes da Lei n. 12.711/2012, foi a Universidade de Brasília (UnB), em 6 de junho de 2003, porém sua implementação ocorreu no segundo semestre de 2004 (SANTOS, 2014).

A Universidade de Brasília adotou, a partir de junho de 2003, um plano chamado "Objetivos para Integração Étnica, Racial e Social", que estabelecia três metas: cota de 20\% para candidatos negros; admissão de estudantes indígenas por meio de um convênio com a Funai; e intensificação do apoio ao sistema de ensino público local. (FERES JUNIOR, 2009, p. 44).

Segundo Santos (2014), a UnB foi pioneira, dentre as instituições superiores federais, em debater sobre a indispensabilidade de Ações Afirmativas como medidas de enfrentamento ao racismo, sobretudo por ocasião do Seminário Internacional Multiculturalismo e Racismo, realizado em suas dependências. 
A Lei Federal n. 12.711, de 29 de agosto de 2012, conhecida como Lei de Cotas, dispõe sobre a reserva de vagas em universidades federais para estudantes de baixa renda oriundos/as de escolas públicas, pretos/a, pardos/as e indígenas, bem como para aqueles/as com deficiência, como é apresentado nos Artigos 1 으 e 3 o da referida Lei:

Art. 1을 As instituições federais de educação superior vinculadas ao Ministério da Educação reservarão, em cada concurso seletivo para ingresso nos cursos de graduação, por curso e turno, no mínimo 50\% (cinquenta por cento) de suas vagas para estudantes que tenham cursado integralmente o ensino médio em escolas públicas.

Art. 3 o Em cada instituição federal de ensino superior, as vagas de que trata o art. 1 - desta Lei serão preenchidas, por curso e turno, por autodeclarados pretos, pardos e indígenas e por pessoas com deficiência, nos termos da legislação, em proporção ao total de vagas no mínimo igual à proporção respectiva de pretos, pardos, indígenas e pessoas com deficiência na população da unidade da Federação onde está instalada a instituição, segundo o último censo da Fundação Instituto Brasileiro de Geografia e Estatística - IBGE. (BRASIL, 2012).

Esta Lei, sancionada pela então Presidenta Dilma Rousseff, produziu perspectivas de homogeneização dessas ações em todo território brasileiro. Desse modo, em 2013, um ano após a sua criação, o índice obrigatório de reserva de vagas deveria ser de 12,5\%, o que significa, segundo Fernandes (2013), que metade das vagas das universidades federais seria designada aos/às estudantes advindos/ as de escolas públicas, as quais deveriam ser ocupadas por negros/as, pardos/ as e indígenas, proporcionalmente à composição do contingente populacional do estado no qual se encontra a instituição. Por conseguinte, até o ano de 2016, todas as universidades federais precisariam assegurar a taxa mínima de 50\% para a reserva de vagas estipulada pela Lei (BRASIL, 2015).

Conforme publicação da SEPPIR, de 2013 a 2015, 150 mil negros/as ingressaram nas universidades utilizando o sistema de cotas. Segundo a Secretaria, em 1997, o índice da população negra com idade entre 18 e 24 anos, que fazia ou já havia concluído o Ensino Superior, era de 1,8\%, e o de pardos/as, 2,2\%. Em 2013, esses indicadores evoluíram, na devida ordem, para 8,8\% e 11\%. Em seguida, a taxa de reserva de vagas determinada pela Lei n. 12.711 para o teto mínimo de 50\% já havia alcançado, em 2014, os 40\% (BRASIL, 2016). 
O Censo da Educação Superior realizado em 2014 mostra que até então existiam no Brasil 107 instituições federais. Destas, 91,6\%, ou seja, 98 estabelecimentos federais de Ensino Superior já possuíam algum programa de reserva de vagas, atendendo desse modo ao que está definido no Plano Nacional de Educação (PNE), bem como aos seguintes condicionantes: alunos de ensino público, renda familiar, etnia etc. Quando se trata da reserva de vagas exclusivamente de cunho étnico, os dados do Instituto Nacional de Estudos e Pesquisas Educacionais Anísio Teixeira mostram que 94 instituições federais já assumiam esta prática, ou seja, $88 \%$ do total (INEP, 2016).

Quanto às instituições estaduais de Educação Superior, o Inep (2016) relata que há no país 120 estabelecimentos, dos quais 91, ou seja, 75,8\%, possuem programa de reserva de vagas (PNE, alunos de ensino público, renda familiar, etnia, entre outras). No que se refere à reserva de cunho étnico, do total de 120 instituições estaduais, 65\% já utilizam tal programa, ou seja, 78 estabelecimentos. Pode-se dizer, então, que a maioria das instituições públicas de Ensino Superior do Brasil já utiliza o sistema de cotas, sobretudo em consonância com a Lei n. $12.711 / 2012$.

Apesar desses avanços, a quantidade de negros/as e indígenas ainda é baixa. Do total de 1,2 milhão de ingressantes nas universidades federais, por exemplo, apenas 7,6\% são negros/as, o que corresponde a 92.698 estudantes. Os indígenas representam índice de 0,6\%, ou seja, 7.392 universitários. Os/as pardos/as compreendem $27,5 \%$ o que significa 333.838 estudantes. Os/as brancos/as que frequentam as universidades federais configuram 34\%, o que significa 411.887 estudantes (INEP, 2016). Porém, ao observar o "aumento da resposta 'Não declarada', que, entre os ingressantes, partiu de 23,1\% em 2013 para 33,7\% em 2014, crescimento superior a dez p.p.", o cenário apresentado, provavelmente, revelaria uma nova configuração (SENKEVICS, 2017, p. 24).

A política de cotas, sem dúvidas, permitiu avanço significativo no ingresso aos espaços acadêmicos das camadas vulneráveis da sociedade brasileira. Assim como mostra uma notícia publicada em 2015 pelo Portal GELEDÉS, salientando que na última década o número de negros nas universidades brasileiras aumentou em 230\%, "inegavelmente houve uma abertura acentuada permitindo a entrada de estudantes provenientes de setores anteriormente excluídos desse nível de escolarização" (BARBOSA, 2015). 


\section{ASPECTOS METODOLÓGICOS}

Essa pesquisa se fundamenta na perspectiva relacional potencializada por Pierre Bourdieu, que, não obstante, apresenta críticas aos pensamentos positivistas de um cosmo social fechado e visualizado de forma homogênea por todos aqueles que dele fazem parte. Para tanto, é fundamental, a princípio, ilustrar as teorias de campo e habitus de Bourdieu. É importante considerar que o campo em análise é o acadêmico superior.

Bourdieu intitula campo o locus em que acontecem o encontro e as inter-relações entre as hierarquias, "o espaço social de relações objectivas" (BOURDIEU; PASSERON, 1992, p. 64). No campo, é ensejada a disputa oponente entre os indivíduos com vistas em interesses ou vantagens distintas que, todavia, configuram a esfera em evidência. O campo não é produto unicamente das ações singulares dos indivíduos, que passam a aceitar e cumprir as regras e os preceitos de ajustamentos que lhe são intrínsecos e que mudam conforme a estrutura do campo. É no campo que se revelam as relações de poder que se constituem mediante a divisão díspar de um determinado capital social, econômico e cultural, o qual define o espaço na hierarquia social ocupado por determinados sujeitos (BOURDIEU; PASSERON, 1992).

A relação dos indivíduos com o mundo social não é algo automaticamente alicerçado em causalidades, que, quase sempre, se fundam na comunicação entre o meio e a consciência, mas sim num tipo de ligação ontologicamente significativa (BOURDIEU, 1989). Os indivíduos, em vista disso, seriam concebidos como o resultado de um entrelaçamento de forças de origem social, de uma socialização que não se finda, até porque a experiência do sujeito "inscreve-se em registros múltiplos e não congruentes" (SETTON, 2011, p. 719).

Com base nessa reflexão, percebe-se que o habitus encontra situação favorável para a sua consolidação e desenvolvimento na lógica do aparelho, "ou, inversamente, na lógica de que o aparelho "explora" em seu proveito as tendências escritas nos habitus" (BOURDIEU, 1989, p. 199).

O conceito de habitus elaborado por Bourdieu, ao mencionar a realidade existencial de uma estrutura estruturada inclinada a se restabelecer como estruturante, a começar tanto pela apropriação da exterioridade pelo indivíduo, quanto da exteriorização de sua subjetividade, agrupa todas as peculiaridades obtidas pelos sujeitos em suas trajetórias de socialização, que são internalizadas 
de forma a permitir-lhes os pensamentos e as competências indispensáveis para a construção de sua "história de vida", tanto individual quanto coletiva.

[...] é na correspondência de estrutura a estrutura que se realiza a função propriamente ideológica do discurso dominante, intermediário estruturado e estruturante que tende a impor a apreensão da ordem estabelecida como natural. (BOURDIEU, 1989, p. 14).

Para Oliveira (2006), o habitus, de acordo com a concepção de Bourdieu, é algo que detém grande força criadora, é um resultado das sujeições que estão propensas a reproduzir o sentido objetivo destas, porém incorporando nelas modificações. É um tipo de mecanismo de transfiguração que nos impulsiona a reproduzir a conjuntura social de nossa própria criação.

Sendo assim, essa pesquisa é caracterizada por uma abordagem qualitativa, pois ela "responde a questões muito particulares. [...] com um nível de realidade que não pode ou não deveria ser quantificado" (MINAYO, 2015, p. 21). Sua estratégia busca combinar a praxeologia bourdieusiana com a construção do objeto real, ou seja, com a completude das relações da realidade social. "O objeto construído, por sua vez, constitui uma tradução, uma versão do real a partir de uma leitura orientada por conceitos operadores" (MINAYO, 2015, p. 33).

Logo, para a composição do universo de entrevistadas, priorizamos aquelas que concebemos, à luz da perspectiva teórica de Amado e Ferreira (2013), como sendo testemunhas privilegiadas que nos possibilitariam "aprender o máximo" (AMADO; FERREIRA, 2013, p. 214). Diante desse fato, preocupamo-nos em trazer para nosso estudo universitárias negras cotistas que "[...] pela sua experiência de vida quotidiana, pelas suas responsabilidades, estatuto, etc., estejam envolvidas ou em contacto muito próximo com o problema que se quer estudar" (AMADO; FERREIRA, 2013, p. 214).

A princípio, contatamos, mediante cartas-convites, as pesquisadas que se autodefiniram negras, frequentes no último semestre dos cursos de Licenciatura em Filosofia e Ciências Sociais. A escolha por trabalhar com esses cursos se deve ao fato de que ambos foram instituídos a partir de 2008, ano que marca a implementação do sistema de cotas na Universidade Estadual do Sudoeste da Bahia.

Com a anuência das pesquisadas, foram marcadas as entrevistas individuais, orientadas por um guião de entrevistas. A técnica da entrevista semiestruturada 
nos permitiu maior acesso "aos discursos dos indivíduos, tal como estes se expressam, ao não observável [...]" (AMADO; FERREIRA, 2013, p. 211).

Os perfis das unidades de investigação se assemelham nas condições socioeconômicas. Apresentam faixa etária que oscila entre os 22 e 28 anos. A maioria trabalha e todas ingressaram na universidade pelo sistema de cotas. As entrevistadas possuem outra característica comum: são oriundas da escola pública e de famílias com escasso capital cultural e econômico.

\section{COTAS RACIAIS E PROMOÇÃO DA IGUALDADE: EXPERIÊNCIAS DE ALUNAS NEGRAS UNIVERSITÁRIAS}

No contexto da universidade, espaço de poder hegemonicamente elitista e branco, a reprodução institucional de prerrogativas ocorre instintivamente. As transformações, diante desse fato, reivindicam uma justificativa daqueles marginalizados, que demandam cotas para negros. Isso significa, no que cerne ao contingente negro, que as cotas precisam ser confessas. É nessa ocasião que se erigem os limites, as barreiras, as resistências. Entraves entrepostos em defesa dos privilégios (BENTO, 2005). Tais obstáculos inseridos no processo de alteração da alocação de negros e brancos na universidade são estáveis, profundos, fortes e não se curvam com facilidade (BENTO, 2005).

Apesar da anuência, por parte de alguns, de que negros têm menos chances do que brancos, a relutância à instituição de políticas de reparação das implicações engendradas a partir de ações racialmente discriminatórias, diante do racismo fortemente marcado na sociedade brasileira, é significantemente imensa. Para Bento (2005, p. 45), os argumentos que endossam essa resistência são frágeis, porém continuam a se repetir: [...] "essas políticas são assistencialistas, protecionistas, geram a discriminação às avessas". Parecem ser, esses argumentos, manifestações contra a suposta falta de isonomia que acomete os brancos perante a viabilidade de políticas que contemplam, essencialmente, negros e negras.

Tais premissas, associadas ao pretexto de inconstitucionalidade das cotas raciais, sustentado por outros, indicam que esse conjunto de argumentos somente desponta na pauta de discussão quando a proposta de cotas é indicada como viés de inserção de negros/as nas instituições públicas brasileiras de Ensino Superior (BENTO, 2005). 
Contudo as experiências de adoção de cotas raciais em andamento demonstram que tais instituições têm oportunizado o ingresso de jovens negros/as nos espaços universitários, os quais não estavam habituados com a mobilidade desses atores sociais nos seus interiores, tampouco com a corporeidade negra, que traz consigo novas experiências e significados (GOMES, 2009). "São corpos negros ativos e afirmativos que se contrapõem à ideologia de cor e do corpo do brasileiro" (GOMES, 2009, p. 202).

Nessa esteira, as cotas raciais, bem como outras políticas de Ações Afirmativas, têm proporcionado avanços rápidos em pouco tempo. Por outro lado, o conjunto de medidas reparatórias "não têm propiciado uma efetiva igualdade, apesar de terem na igualdade a sua essência teórica" (SANTOS, 2009).

Ao adentrarem num espaço elitizado, racializado e marcadamente sexista como a universidade, as mulheres negras, para além da luta contra a tríplice opressão, empenham-se no "resgate das suas histórias, recriando em suas potencialidades a tentativa de buscar mudanças que permitam novas experiências relacionais de poder na sociedade" (MOREIRA, 2011). Pode-se dizer que, provavelmente, tais mudanças são pensadas a partir de uma condição de desigualdade social que tem seus fundamentos nas questões de gênero, raça e classe enquanto princípios preponderantes da organização social.

Nesse contexto, ao refutar o que a sociedade Ihe outorga, a mulher negra externa a sua compreensão sobre a situação de discriminação da qual é vítima e, consequentemente, passa a se dedicar à luta pelo reconhecimento de seus valores e dignidade. Numa análise analógica do universo das mulheres brancas e negras, notam-se visões divergentes sobre a vida, a família e as relações sociais, que, não obstante, são diferentes e regidas pelos determinantes socioeconômicos e raciais. Dessa forma, "as mulheres negras que pertencem às classes mais pobres, pouco escolarizadas, vivem no dia-a-dia a desvalorização pessoal e têm consciência de que são diferentes das mulheres brancas" (OLIVEIRA, 2006).

$\mathrm{Na}$ tentativa de amenizar esta situação, a mulher negra tem buscado a universidade como um dos caminhos para eliminar as práticas de inferiorização relacionadas às dessemelhanças inerentes à raça, classe e gênero. Assim, o Ensino Superior se configura como viés possível de enfrentamento das desigualdades e de transformação social. 
Diante das idiossincrasias históricas que permeiam a população negra no Brasil, é importante ressaltar a necessidade do desvencilhamento do "não saber o que fazer ou pensar" que permeia o contexto atual brasileiro de oscilações e dá início a uma fase de descontinuidades dessa estagnação social e exclusão que perdura há séculos. A política de cotas raciais, nesse sentido, auxilia de modo significativo nessa direção (SANTOS, 2009). Com efeito, as estudantes negras cotistas, sujeitos desse estudo, através de suas narrativas, expõem a importância das cotas raciais para o ingresso na universidade, argumentando que elas "[...] são de suma importância, uma vez que negros e negras, historicamente perseguidos e vulnerabilizados, as têm como uma forma de reparação" (E4.1). Consideram "[...] que a qualidade do ensino público não é equânime; portanto as cotas raciais se tornam essenciais, porque nem todos podem pagar por um cursinho particular" (E.2). Desse modo, o sistema de cotas "[...] é muito importante, pois é uma possibilidade a mais de ingresso na universidade, haja vista que a escola pública nem sempre oferece uma educação de qualidade" (E.3). Nesse sentido, as cotas são "[...] possibilidades de acesso ao Ensino Superior" (E.4).

A política de cotas para essas estudantes que vêm de escola pública surge como um canal viável de inserção na universidade. As dificuldades de ingresso enfrentadas por elas no espaço institucional "podem ser associadas ao funcionamento geral do sistema de ensino brasileiro, extremamente desigual em termos de qualidade oferecida aos alunos provenientes de distintos grupos sociais" (BARBOSA, 2015).

Os depoimentos colhidos permitiram avaliar que a inserção dessas jovens no mundo ainda desconhecido da universidade teve impactos consideráveis, a julgar as disparidades da qualidade educacional que elas experienciaram. As cotas raciais nas suas trajetórias de escolarização surgiram como um descerramento para o campo do conhecimento, antes não idealizado por elas. Dentro de cada depoimento, pode se notar a relevância das cotas raciais nas próprias trajetórias escolares; "é uma maneira política de assegurar e legitimar o espaço do segmento negro" (E.1) no universo acadêmico, "desde os congressos à iniciação científica, ou uma tarde de estudos na biblioteca, ocupando um espaço não ocupado antes. A universidade ainda é formada pela classe média e branca" (E.2). A opção pelas

\footnotetext{
${ }^{4}$ Utilizou-se a letra "E" para indicar a categoria "estudante", seguida do numeral arábico para relacionar a ordem das falas. Todas as entrevistas foram realizadas em 2017.
} 
cotas se justifica, portanto, no sentimento de negação "do direito de ter grandes ambições, por ser cria de uma casa preta, por vir do ensino público, [...] o que dificultaria a chance de ingressar no Ensino Superior" (E.4).

As narrativas indicam, para além de interpretações que se repetem, a qualidade discrepante do sistema de ensino público, o que dificulta uma concorrência igual entre todos aqueles que buscam acessar o Ensino Superior, outro aspecto importante que diz respeito às maiores distinções absolutas que favorecem os/as brancos/as. Diante de situações de grande competição, como o vestibular, as cotas raciais possibilitaram, inquestionavelmente, "uma abertura acentuada permitindo a entrada de estudantes provenientes de setores anteriormente excluídos desse nível de escolarização" (BARBOSA, 2015).

De uma forma ou de outra, incontestavelmente, as informações demonstram a existência de outros problemas estruturais da sociedade brasileira que precisam ser solucionados, como "a pobreza dos negros e a baixa qualidade da escola pública", e ainda, "além de problemas de ordem econômica, os negros enfrentam também problemas relacionados com preparação insuficiente e pouca persistência e motivação" (GUIMARÃES, 2003). "Pessoas que vêm de origem negra e pobre não são estimuladas a galgar a universidade" (E.4).

De acordo com Guimarães (2003, p. 258):

Problemas desse tipo acompanham todas as minorias que vivenciaram posição social subalterna por um longo período de tempo, seja porque os laços comunitários são ainda fracos, seja porque o grupo não desenvolveu uma estratégia eficiente de reversão de sua posição de subordinação.

Nesse contexto, a desigualdade social e racial possui um potente elemento regional, materializado na concentração de capital econômico na parte Sudeste do país em detrimento da Região Nordeste. Possui, do mesmo modo, uma resistente tendência local, principalmente nas áreas urbanas mais extensas onde se multiplicam as favelas, local de moradia de milhares de pessoas. Existe ainda a questão de gênero, que contribui para que uma fração considerável das mulheres, marcadamente as mulheres negras, especialmente as que chefiam famílias, mantenha-se nos estratos que recebem os mais baixos rendimentos (JACCOUD; THEODORO, 2005).

Diante da realidade das cotas raciais no Brasil e do seu sentido político de se fazer reconhecer o Ensino Superior de qualidade como uma prerrogativa aos/ às negros/as, foi inquirido às estudantes o seu entendimento sobre a dificuldade, 
ou não, do próprio ingresso na universidade caso não existisse a política de cotas raciais. A maioria compartilhou do mesmo pensamento. Certamente, para elas, o caminho até a universidade seria difícil, acometido por alguns fatores que, em decorrência de suas particularidades e subjetividades, limitariam suas expectativas, esperanças e êxitos. "[...] sem o sistema de cotas seria difícil, uma vez que já enfrentamos dificuldades nas escolas públicas, preconceitos e desigualdade" (E.3). Em vista disso, "[...] ingressar em uma universidade pública não é fácil no Brasil, porque desde cedo as condições de estudos basilares não são as mesmas para todos" (E.1).

Com efeito, esse panorama de desigualdade social e racial explica a existência de discrepâncias na educação mediante as distinções sociais e de rendimento entre negros/as e brancos/as no Brasil. "Ou seja, poder-se-ia pensar que os alunos negros são oriundos de família de menor renda e de menor nível educacional que os brancos, e, por isso, encontrariam maiores dificuldades em sua trajetória escolar" (JACCOUD; THEODORO, 2005).

Dessa forma, refletir sobre a conviç̧ão da evolução social viabilizada pela escola, ainda que "as condições econômicas de existência são condições necessárias, mas seguramente não suficientes" (LAHIRE, 1997), parece ser estimulado pela vontade das entrevistadas de ocupar um espaço na universidade antes a elas negado. A utilização da política de cotas raciais como mecanismo de ingresso no sistema de Ensino Superior permite perceber que "a boa vontade cultural pura e esvaziada, inteiramente definida pelos imperativos da ascensão, tem seu equivalente no plano moral" (BOURDIEU, 2015).

Como espaço elitizado, a universidade vai funcionar como instrumento capaz de possibilitar a essas estudantes o "direito de ocupar posições sociais, além de reduzir os efeitos de isolamento, associados à existência de espaços sociais dotados de seus princípios de hierarquização" (BOURDIEU, 2015). Nesse sentido, a política de cotas pode ensejar um clima de concorrência mais equânime, mais aproximado daquilo que se espera, tanto na academia quanto nas profissões (CARVALHO, 2009).

Desse modo, para as estudantes pesquisadas, tantos as cotas raciais quanto a universidade se configuram como orientações possíveis de ascensão social e amenização da desigualdade. Essa desigualdade, segundo Barbosa (2009), "não é apenas contabilidade de diferenças, mas um tipo de organização social específico, [...] que transforma essas diferenças em desigualdades sociais" (BARBOSA, 2009). 


\section{CONCLUSÃO}

Diante dos argumentos apresentados, os quais possibilitaram o debate sobre a política de cotas raciais na perspectiva de mulheres negras universitárias, os resultados apontaram para as relevantes mudanças de participação por cor/ raça de frações sociais e que tais mudanças são temporais e geracionais. Contudo, ainda que as cotas funcionem como um dos mecanismos relevantes de acesso do segmento negro ao Ensino Superior, alcançar a equidade é um processo demorado, portanto elas ainda não promoveram, como desejado, a mitigação dos distanciamentos raciais e sociais.

Isso é corroborado pelos últimos dados do IPEA que mostram as disparidades que ainda persistem entre negros/as e brancos/as nas instituições universitárias do Brasil. Essas dessemelhanças, contudo, refletem-se no campo profissional, impactando especialmente as mulheres negras que ainda sofrem com o racismo e sexismo no mercado de trabalho.

A política de cotas raciais, enquanto política de Ação Afirmativa, apesar de ser considerada de fundamental importância pelas estudantes que compunham este estudo, não conseguiu amenizar o racismo, tampouco foi inclusiva o bastante para contemplar todo o contingente negro. Mesmo tendo promovido uma ampliação de reservas de vagas, ela também não subsidia condições de permanência para os/as estudantes beneficiados/as.

Por outro lado, assim como fora exposto nas narrativas das entrevistadas, os/as negros/as desejam usufruir da mobilidade universitária, experienciar o melhor que a universidade possa dispor e ocupar o espaço dos possíveis. Diante das condições competitivas díspares, traduzidas na baixa qualidade do ensino público, valem-se das cotas como viés de reparação. No entanto elas não podem ser confundidas como desígnios para a diminuição da pobreza das camadas populares. Mas, se triunfantes, poderão transformar a realidade da Educação Superior brasileira, através da igualdade de oportunidade e do rompimento da linha divisória de discriminação racial. 


\section{REFERÊNCIAS}

AMADO, João; FERREIRA, Sónia. A entrevista na investigação educacional. In: AMADO, João (Coord.). Manual de investigação qualitativa em educação. Imprensa da Universidade de Coimbra, Portugal, 2013.

AZEVEDO, Celia Maria Marinho de. Cota racial e Estado: abolição do racismo ou direitos de raça? Cadernos de Pesquisa, São Paulo, v. 34, n. 121, p. 213-39, jan./abr. 2004.

BARBOSA, Maria Ligia Oliveira. Destinos, escolhas e a democratização do Ensino Superior. Política \& Sociedade, Florianópolis, v. 14, n. 31, set./dez. 2015.

BARBOSA, Maria Ligia Oliveira. Desigualdade e desempenho: uma introdução à sociologia da escola brasileira. Belo Horizonte, MG: Argvmentvm, 2009.

BENTO, Maria Aparecida Silva. Branquitude e poder: a questão das cotas para negros. In: SANTOS, Sales Augusto dos (Org.). Ações afirmativas e combate ao racismo nas Américas. Brasília: Ministério da Educação, Secretaria de Educação Continuada, Alfabetização e Diversidade, 2005.

BOURDIEU, Pierre. A distinção: crítica social do julgamento. 2. ed. rev., 2. reimpr. Porto Alegre, RS: Zouk, 2015.

BOURDIEU, Pierre; PASSERON, Jean Claude. A reprodução: elementos para uma teoria do sistema de ensino. Rio de Janeiro: Francisco Alves, 1992.

BOURDIEU, Pierre. O poder simbólico. Rio de Janeiro: Bertrand Brasil; São Paulo: Difel, 1989.

BRASIL. Secretaria Especial de Políticas de Promoção da Igualdade Racial. Em 3 anos, 150 mil negros ingressaram em universidades por meio de cotas. Brasília, 2016. Disponível em: https://www.mdh.gov.br/noticias_seppir/noticias/2016/03-marco/em-3-anos-150mil-negros-ingressaram-em-universidades-por-meio-de-cotas. Acesso em: 17 maio 2018.

BRASIL. A democratização e expansão da educação superior no país 20032014. Brasília, DF, 2015. Disponível em: http://portal.mec.gov.br/index.php?option=com docman\&view=download\&alias=16762-balanco-social-sesu-2003-2014\&ltemid=30192. Acesso em: 16 ago. 2018.

BRASIL. Lei n. 12.711, de 29 de agosto 2012. Dispõe sobre o ingresso nas universidades federais e nas instituições federais de ensino técnico de nível médio e dá outras 
providências. Brasília, DF, 2012. Disponível em: http://www.planalto.gov.br/ccivil_03/_ ato2011-2014/2012/lei/l12711.htm. Acesso em: 2 mar. 2018.

CARVALHO, José Jorge de. Ações afirmativas na pós-graduação, na docência superior e na pesquisa. In: SILVÉRIO, Valter Roberto; MOEHLECKE, Sabrina (Org.). Ações afirmativas nas políticas educacionais: o contexto pós-Durban. São Carlos, SP: EDUFSCar, 2009.

DAFLON, Verônica Toste; FERES JUNIOR, João; CAMPOS, Luiz Augusto. Ação afirmativa, raça e racismo: uma análise das ações de inclusão racial nos mandatos de Lula e Dilma. Revista de Ciências Humanas, Viçosa, MG, v. 12, n. 2, p. 399-414, jul./dez. 2012.

FERES JUNIOR, João. Ação afirmativa no Brasil: a política pública entre os movimentos sociais e a opinião douta. In: SILVÉRIO, Valter Roberto; MOEHLECKE, Sabrina (Org.). Ações afirmativas nas políticas educacionais: o contexto pós-Durban. São Carlos, SP: EDUFSCar, 2009. Cap. 1.

FERNANDES, Rosa Maria Castilhos. Educação e desigualdade social: quando as minorias étnicas adentram a Universidade. In: MEIRELLES, Mauro et al. (Org.). Ensino de Sociologia: diversidade, minorias, intolerância e discriminação social. Porto Alegre: Evangraf/LAVIECS, 2013.

GOMES, Nilma Lino. Para além das bolsas acadêmicas: ações afirmativas e o desafio da permanência dos(as) jovens negros(as) na universidade pública. In: SILVÉRIO, Valter Roberto; MOEHLECKE, Sabrina (Org.). Ações afirmativas nas políticas educacionais: o contexto pós-Durban. São Carlos, SP: EDUFSCar, 2009.

GUIMARÃES, Antonio Sérgio Alfredo. Contexto histórico-ideológico do desenvolvimento das ações afirmativas no Brasil. In: SILVÉRIO, Valter Roberto; MOEHLECKE, Sabrina (Org.). Ações afirmativas nas políticas educacionais: o contexto pós-Durban. São Carlos, SP: EDUFSCar, 2009. Cap. 1.

GUIMARÃES, Antonio Sérgio Alfredo. Acesso de negros às universidades públicas. Cadernos de Pesquisa, São Paulo, n. 118, p. 247-268, mar. 2003. Disponível em: http:// www.scielo.br/pdf/cp/n118/16836.pdf. Acesso em: 9 maio 2018.

INSTITUTO NACIONAL DE ESTUDOS E PESQUISAS EDUCACIONAIS ANÍSIO TEIXEIRA (INEP). Sinopse Estatística da Educação Superior 2015. Brasília: Inep, 2016. Disponível em: http:// inep.gov.br/sinopses-estatisticas-da-educacao-superior. Acesso em: 5 maio 2018.

INSTITUTO DE PESQUISA ECONÔMICA APLICADA (IPEA). Retrato das desigualdades de gênero e raça. Brasília: Ipea, 2016. Disponível em: http://www.ipea.gov.br/retrato/ indicadores_educacao.html. Acesso em: abr. 2018. 
INSTITUTO DE PESQUISA ECONÔMICA APLICADA (IPEA). Ouvidoria. [e-Ouv - Sistema de Ouvidorias] Manifestação Respondida no Sistema sobre Censo da Educação Superior 2015/INEP. [mensagem pessoal]. Disponível em: Ouvidorias@cgu.gov.br. Acesso em: 21 ago. 2017.

JACCOUD, Luciana (Org.). A construção de uma política de promoção da igualdade racial: uma análise dos últimos 20 anos. Brasília: Ipea, 2009.

JACCOUD, Luciana; THEODORO, Mário. Raça e educação: os limites das políticas universalistas. In: SANTOS, Sales Augusto dos (Org.). Ações afirmativas e combate ao racismo nas Américas. Brasília: Ministério da Educação, Secretaria de Educação Continuada, Alfabetização e Diversidade, 2005.

LAHIRE, Bernard. Sucesso escolar nos meios populares: as razões do improvável. São Paulo: Ática, 1997.

LIMA, Márcia. Desigualdades raciais e políticas públicas: ações afirmativas no governo Lula. Novos estudos - CEBRAP, São Paulo, n. 87, p. 77-97, jul. 2010.

LOPES, Robson da Silva. O movimento negro no Brasil: lutas e conquistas em prol de uma sociedade equânime. 2014. Disponível em: http://www.pordentrodaafrica.com/ wp-content/uploads/2014/08/Movimento-Negro-Brasileiro-Robson-S.-Lopes.pdf. Acesso em: 24 out. 2018.

MINAYO, Maria Cecília de Souza (Org.). Pesquisa social: teoria, método e criatividade. 34. ed. Petrópolis, RJ: Vozes, 2015.

MOREIRA, Núbia Regina. A organização das feministas negras no Brasil. Vitória da Conquista, BA: Edições UESB, 2011.

OLIVERIA, Eliana de. Mulher negra - professora universitária: trajetória, conflitos e identidade. Brasília: Líber Livro, 2006.

SANTOS, Hélio. Desenvolvimento e diversidade étnico-racial. In: SILVÉRIO, Valter Roberto; MOEHLECKE, Sabrina (Org.). Ações afirmativas nas políticas educacionais: o contexto pós-Durban. São Carlos, SP: EDUFSCar, 2009.

SANTOS, Sales Augusto dos. Ações afirmativas nos governos FHC e Lula: um balanço. Tomo - Revista do Programa de Pós-Graduação em Sociologia da Universidade de Sergipe, n. 24, p. 37-84, jan./jun. 2014. Disponível em: https://seer.ufs.br/index.php/tomo/article/ view/3185/0. Acesso em: 31 abr. 2018. 
SENKEVICS, Adriano Souza. Cor ou raça nas instituições federais de ensino superior: explorando propostas para o monitoramento da Lei de Cotas. Brasília: Instituto Nacional de Estudos e Pesquisas Educacionais Anísio Teixeira, 2017.

SETTON, Maria Graça Jacintho. Teorias da socialização: um estudo sobre as relações entre indivíduo e sociedade. Educação e Pesquisa, São Paulo, v. 37, n. 4, p. 711-24, dez. 2011.

\section{Sobre os autores:}

João Paulo Lopes dos Santos: Mestrando em Educação do Programa de PósGraduação em Educação da Universidade Estadual do Sudoeste da Bahia (PPGED/ UESB). Departamento de Filosofia e Ciências Sociais. E-mail: jpuesb@gmail.com, Orcid: http://orcid.org/0000-0001-8825-1741

Nubia Regina Moreira: Doutora em Sociologia e professora do Mestrado em Educação do Programa de Pós-Graduação em Educação da Universidade Estadual do Sudoeste da Bahia (PPGED/UESB). E-mail:nreginamoreira@hotmail.com, Orcid: http://orcid.org/0000-0001-6171-6756

Recebido em dezembro de 2018.

Aprovado em maio de 2019. 